\title{
IMPACT OF MEDIA QR CODE TO GROW THE INTEREST OF STUDENTS LEARN SOCIOLOGY IN SOCIAL CONFLICT MATERIALS
}

\author{
Anna Rusmiyati \\ SMPN 1 Pulung Ponorogo \\ e-mail: annarusmiyati@yahoo.co.id
}

\begin{abstract}
The existence of innovative learning allows dynamism in learning. The presence of technology in the world of education is to help teachers and students to obtain the speed of information, create innovative learning, and facilitate all teaching and learning activities. One result of technology that can be utilized in learning is the presence of a smartphone. On the smartphone, there is a QR Code media that can be downloaded via Google Play. One of the sociological materials, namely social conflict is the choice to be presented with QR Code media. The implementation is that students from one of the groups download the QR Code on their smartphone so that they can scan the assignments given by the teacher in the form of barcodes. Previously the teacher had prepared questions about the subject of social conflict in the form of barcodes. Gurupun also download a barcode generator on a smartphone to be able to write the problem, then the final result in the form of a barcode. The results in the form of barcodes are then printed. Then students do the scanning on the printed barcode and the task or problem to appear will appear. Completion of tasks is done in groups so as to accelerate the process. Learning with QR Code media also includes 21 st century educational abilities, including literacy, strengthening character education, and 4C (critical, communicative, collaborative, and creative). By using the QR Code media it turns out to be very effective in fostering students' interest in studying sociology.
\end{abstract}

Keywords : Innovative learning, QR Code, Barcode Generator, Scaning, Social Conflict

\section{INTRODUCTION}

Willingness is a powerful motivation for a person to make a change. Likewise with teachers who are aware of their duties and responsibilities to prepare future generations who are able to communicate, collaborate, think critically and also creatively. The great power in a teacher to change is his students. Teaching with the heart makes us moved to help students' learning difficulties. Facing students every day 
is actually a golden opportunity to be able to instill goodness in their souls. That is why the cultivation of productive knowledge will produce productive generations. Likewise, when a teacher instills a wrong education, then what happens is also a mistake in the generation that applies it.

One branch of social science is sociology, in which it is always related to humans and all forms of effects and causes of social relations. As a social science, surely an appropriate way is needed to easily understand the basic concepts of social relations in society. In SMAN 1 Pulung, sociology is one of the subjects of specialization in social majors. As one of the specialization subjects, the existence of sociology should really be of interest to the students. But in reality, some students still consider sociology to be a boring, boring and always sleepy class. The students are more engrossed in chatting alone with their classmates discussing matters of the teenage world or even opening gadgets to play online games or view YouTube movies. Students prefer these activities when the teacher who explains the material in front of the class tends to be monotonous, lacks humorous, and saturates. The impact is students are more preoccupied with their own activities, and the teacher in front of the class does not realize because he is too focused on presenting the material. So that the learning that takes place can not be maximized and does not match the learning objectives written in the learning implementation plan.

Departing from the previous statement that "sociology is a sleepy subject", the writer tries a new learning model that is relevant to the development of the world of science and technology. Because the authors believe that learning if it is packaged with interesting and innovative models, students will be interested and also make it easier to understand. And vice versa, if the learning model presented is less interesting as a result students are not listening, busy themselves so that learning objectives are not achieved. The low motivation of student learning is suspected because the teacher learning model is monotonous, boring, and less innovative. Students are not given the opportunity to think and develop their memory in the face of a problem. This is in line with the low opinion of learning outcomes because the classroom atmosphere tends to be teachercentered so that students become passive (Trianto, 2007: 6). In essence what is said as a learning model is a form of presentation that is mastered by the teacher to teach or present lessons to students both individually and in groups with the goal of learning can be absorbed, understood, and utilized by students. Monotonous learning models and methods, such as lectures, are slowly shunned by students. Because in addition to the material presented does not encourage students to think critically, creatively, collaboratively, and communicatively it also results in boredom and makes them sleepy during learning.

Nowadays it has become a social phenomenon where people actively use gadgets in all places and situations. The presence of the gadget is more functioned to simply display one's existence, prestige, or to go along with fashion. Conditions like this also occur in our world of education. It is undeniable that teachers and students often use gadgets not in their place. The teachers themselves often use gadgets to post 
impolite writing, upload photos of themselves excessively, busy chattingan and selling online while teaching in class. Finally, don't be blamed when students roll in to imitate the same activities that their teachers do. Phenomena that have such adverse effects must be avoided immediately. Because it can threaten changes in the character of students.

In the social sciences specialization class at SMAN 1 Pulung when lessons take place there is a tendency for students at a time to often chat, sometimes play gadgets, feel sleepy, daydream, some even cross out or draw on paper. This activity can almost be found in every subject delivered by the teacher in the social sciences class. Gadgets for students seemed to be the main requirement, because it can be seen every few minutes, always open the gadget. That is why a learning contract is needed between the teacher and students at the beginning of learning. Every change of lesson and sometimes even when teaching and learning, students are always looking for opportunities to open smartphones. This is done to simply read WhatsApp, BBM, Twitter, line, browse on Google, Facebook, YouTube, and others. What now needs to be watched and watched out for is the tendency among students to use gadgets to play online games. This condition causes low motivation to learn and lack of student focus in learning.

Based on the background description of the existence of gadgets among students who are sometimes still wrong in their use, then the problem formulation arises namely how is the use of the QR Code media in fostering students' interest in learning sociology in social conflict material? The purpose of this research is to find out the benefits of using gadgets in learning. So the gadget is not only used for social media purposes (social media) such as Facebook, WhatsApp, Twitter, BBM, Instagram, Line, BBM, YouTube, etc. But the benefits are more for improvement in learning and also achievement. Besides that, from learning by using QR Code media, it turns out that PPK (Strengthening Character Education) can be generated, such as the attitude of cooperation, mutual cooperation, and mutual tolerance when learning takes place. And in essence, learning with QR Code media is to train students to be more active, creative, innovative, communicative and collaborative in learning

Based on the background description of the existence of gadgets among students who are sometimes still wrong in their use, then the problem formulation arises namely how is the use of the QR Code media in fostering students' interest in learning sociology in social conflict material? The purpose of this research is to find out the benefits of using gadgets in learning. So the gadget is not only used for social media purposes (social media) such as Facebook, WhatsApp, Twitter, BBM, Instagram, Line, BBM, YouTube, etc. But the benefits are more for improvement in learning and also achievement. Besides that, from learning by using QR Code media, it turns out that PPK (Strengthening Character Education) can be generated, such as the attitude of cooperation, mutual cooperation, and mutual tolerance when learning takes place. And in essence, learning with QR Code media is to train students to be more active, creative, innovative, communicative and collaborative in learning 
QR Code media is a learning method using tools such as smartphones. The smartphone itself is one of the most popular gadgets today and is the most widely used in Indonesia. The purpose of this study using the QR Code media is that students are more interested and interested in learning sociology. QR Code is one of the learning methods by downloading from a smartphone where it looks like a code (dot). QR Code is able to store data and then convey information quickly. Furthermore, choosing QR Code media as a learning medium because it utilizes smartphones where the majority of students have it and makes students able to learn sociology with more motivation. Another driving factor is by applying the QR Code learning method, so students have the willingness to discuss problems, solve and present them for discussion together.

QR Code media is a learning method using tools such as smartphones. The smartphone itself is one of the most popular gadgets today and is the most widely used in Indonesia. The purpose of this study using the QR Code media is that students are more interested and interested in learning sociology. QR Code is one of the learning methods by downloading from a smartphone where it looks like a code (dot). QR Code is able to store data and then convey information quickly. Furthermore, choosing QR Code media as a learning medium because it utilizes smartphones where the majority of students have it and makes students able to learn sociology with more motivation. Another driving factor is by applying the QR Code learning method, so students have the willingness to discuss problems, solve and present them for discussion together.

\section{RESEARCH METHODS}

This research was designed using two cycles. Where each cycle consists of two meetings. These cycles consist of four stages, namely planning, implementation, observation, and reflection. The steps in the cycle are (1) action planning, (2) action implementation, (3) observation, and (4) reflection. The steps are explained below.

a) PLANNING

1) The teacher determines the topic / learning material, namely Social Conflict.

2) The teacher prepares a learning plan on Social Conflict material.

3) The teacher prepares tools and media used in learning.

4) The teacher prepares data collection instruments, namely observation sheets, questionnaires, questions grid, question cards, evaluation questions, and assessment sheets

b) IMPLEMENTATION OF ACTIONS

\section{First Meeting}

a. Preliminary

1) Students are motivated by giving several questions relating to social conflict material.

2) Students associate material about social conflict with the reality of life in society. 
3) Preparing students physically and psychologically in initiating learning activities.

4) Provide an overview of the benefits of learning the lesson to be learned.

5) Linking the learning material to be done about understanding with student experience with previous themes.

6) Explain the learning objectives and basic competencies to be achieved.

7) Conveying indicators of achievement of competence about the understanding and factors driving the emergence of conflict.

\section{b. Core activities}

\section{Providing Stimulus (Stimulation}

a) In this activity the teacher asks students to do literacy.

b) Read a reference book about understanding social conflict and the drivers of conflict.

\section{Probem Statement (question/problem identification)}

a) The teacher prepares questions or questions in the form of barcodes. The question was prepared by the teacher beforehand. Written and printed in barcode format and then prepared at the front desk in the class.

b) Then each group representative comes forward to scan the questions using the QR Code.

c) After scanning, the group representative rejoined the group.

d) The results of the scaning in the form of task questions submitted to the group to be discussed together.

\section{Data Collection}

a) Some children do literacy right away looking for solutions to the answers to barcode scanning results.

b) Supporting data to get answers can be obtained through digital literacy or literacy literacy.

\section{Data Processing}

a) Each individual discuss with each other in his group to find answers from the results of scanning questions.

b) From this discussion, individuals can express their opinions or arguments within their group.

c) After being discussed and felt according to what is in the problem then it was written by one of the students on the sheet.

\section{Verification}

Then in turn each group presents the results of their group discussions, while the other groups respond. This is where communication occurs and critical thoughts emerge from students. And the teacher will give an evaluation based on the activeness, criticism and cohesiveness of each group in both presentation and response. 


\section{Generalization (generalization / draw conclusions)}

At this stage all students will provide responses and provide conclusions on learning about the day's material conflict questions. Then at the end of the lesson the teacher continued to conclude that day's learning. (1) Students are given guidance in summarizing important learning points. (2) Students are reminded of the work that must be done looking for pictures about social conflict material.

(3) The teacher provides feedback on the process and learning outcomes

(4) The teacher carries out follow-up activities in the form of assignments, both individual and group assignments.

The place of the research was SMAN 1 Pulung Ponorogo. This place was chosen because besides the writer was a subject teacher of sociology at SMAN 1 Pulung, also the majority of students in the specialization class in the sciences already had a smartphone. The time used in research is when studying sociology. The units of analysis in this study are students who sit in class xi specializing in social sciences.

QR Code is an abbreviation for Quick Respond Code. In other words, the language is interpreted as a quick scan code, or fast scan. This QR Code was developed by a Japanese company namely Denso Wave which is a division of the Denso Corporation in 1994. The purpose of making it is to provide fast information and get fast responses as well. The presence of this code allows the audience to interact with the media that is embedded through a smartphone effectively and efficiently. Users can also generate and print their own QR Code for people.

\section{RESULT AND DISCUSSION}

\section{Use of QR Codes in the world of Education}

Along with the development of time that is always running dynamically, towards progressive changes to be able to realize the goals of life. Likewise with the world of education, more and more students already have smartphones. This condition actually needs to be observed by teachers all over the world with the enormity of the effects of smartphones caused when not used wisely. Many content, features, applications offered on Android phones and students can easily access them. This is where the role of the teacher is required to be able to direct students to use their cellphones appropriately and wisely. Therefore it is also necessary for teachers to utilize the smartphone in learning so students and teachers can learn together. At least smartphones are not only used for social media, chatter, online gaming, but more than that its presence is also able to provide positive benefits for the world of education. One smartphone application that can be used for learning is the QR Code. The use of QR Code was originally only to develop a company's products. But we as teachers and 
students can also use this media for the benefit of education, especially in learning. With the emergence of the idea of QR Code media used in learning increasingly adds to the competence of teachers in explaining the material, while in students also minimize negative activities due to mobile phones. This is where there needs to be a mutual symbiotic collaboration between teachers and students so that it will produce exciting learning that does not saturate.

The use of gadget learning media today is one of the choices in increasing student competence. Almost all activities nowadays often use science and technology (IT). One that is related to IT is utilizing the use of gadgets in learning. This is because that the gadget is not a luxury anymore. The majority of students in SMAN 1 Pulung use gadgets as a communication tool. Even the gadgets that are owned are various kinds of models, from those that have not been touch screen to those who have touch screen. From the old school model to the modern model following the times. Gadgets become media that are often used by students for all their activities. The gadget seems to be a loyal friend and entertainer when happy, sad and wherever we are.

\section{Smartphone}

Another word is a smartphone. That is a mobile phone that has the ability to use and function that resembles a computer. For some people, a smartphone is a phone that works using all operating system software that provides a standard and fundamental relationship for application developers. While for others, a smart phone is just a phone that presents advanced features such as e-mail or electronic mail, internet and the ability to read electronic books or e-books or there is a keyboard as well as connected or connected and VGA connector. In other words, a smartphone or smartphone is a small computer that has the ability of a telephone. Growing demand for sophisticated portable devices has made great progress in processing, memory, screens and operating systems that are outside the cell phone line.

\section{Social Conflict Material}

Social conflict is one of the materials in class xi specializing in odd semester social sciences. This material is very interesting because as long as humans carry out interaction and socialization, that's where the beginning of conflict occurs. Understanding of conflict is a social process of individuals or groups who try to fulfill their objectives by challenging the opposing parties accompanied by threats and / violence. From a sociological perspective, conflict is defined as a social process between two or more people or groups who try to get rid of other parties by destroying or rendering them helpless. Conflict including a form of social interaction is dissociative.

Meanwhile, according to the figure Soerjono Soekanto said that social conflict as a social process of individuals or groups who try to fulfill their objectives by challenging the opposing party, which is accompanied by threats, and or violence. Meanwhile, according to Lewis A. Coser argues that conflict is a struggle regarding 
values or demands for status, power, and resources that are scarce with the intention of neutralizing, injuring, or eliminating opponents. From this interesting material, the author tries a new learning method using smartphone media. It is expected that using the QR Code media will be able to foster students' interest in studying sociology.

\section{Media QR Code in Learning}

Smartphone is used to install the QR Code application on Google Play. Once installed it can be used to scan to see the discussion question material that appears in the form of dots or barcodes. This learning method is very exciting because the implementation is in groups, so that each group will compete with each other in the speed and accuracy of solving the problems contained in the barcode. With learning methods applying QR Code students can identify problems and provide arguments to solve these problems. Broadly speaking, the steps taken in learning with QR Code media are: (1) Teachers and students must prepare a smartphone, (2) If a smartphone does not have a QR Code application, then immediately download and install it on a smartphone via google play, (3) If you don't have time to download it can be done by activating bluetooth and asking another teacher or other students who have installed the QR Code application, (4) Once installed, learn to scan by directing the QR Code camera that has been prepared previously, (5) Teachers or students must be patient when scanning QR Code with a smartphone, (6) At when scanning with the QR Code note the distance between the object and the smartphone, adjust so that the object is in the camera frame so that the object can be read quickly, (7) During the scanning process with the QR Code, also pay attention to the lighting of the object not to be too bright, (8) If you want save the results of the scan so the teacher or student can do it with a screenshot on his smartphone, (9) Keep maintaining security and cleanliness and the lens on the smartphone so it can be comfortable when used.

\section{QR Code Generator}

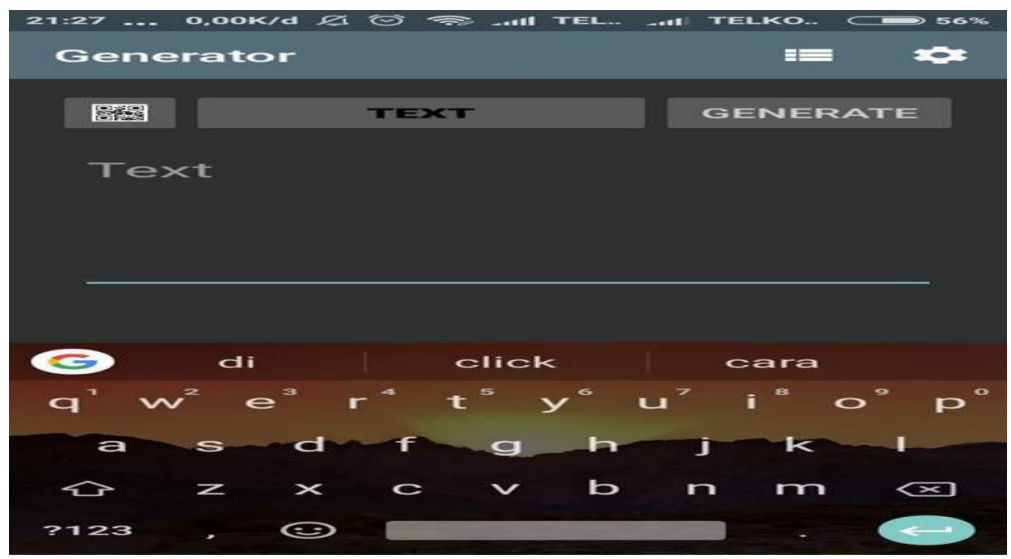


Figure 1. Form QR Code Generator

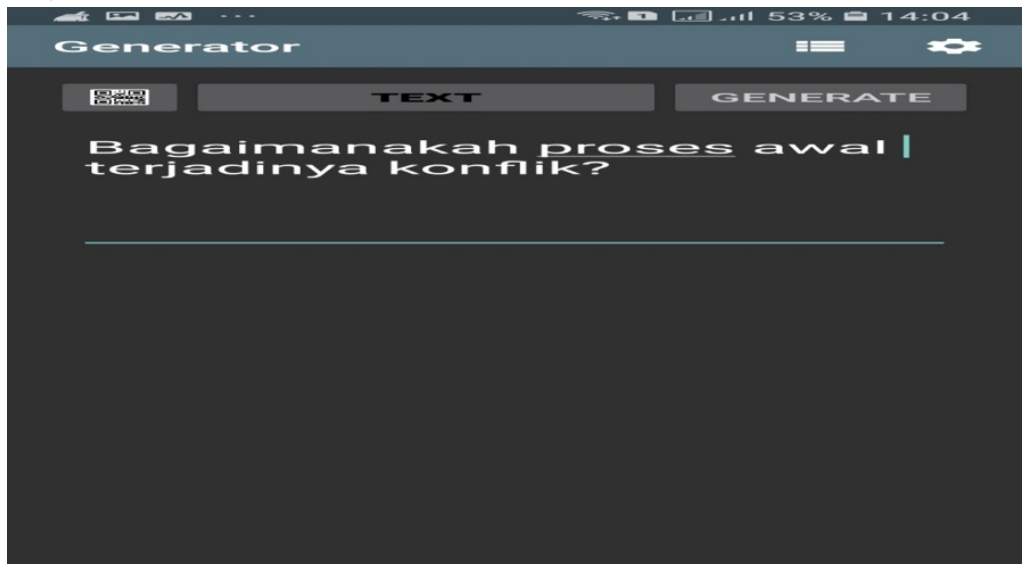

Figure 2. Problems typed in the QR Barcode Generator

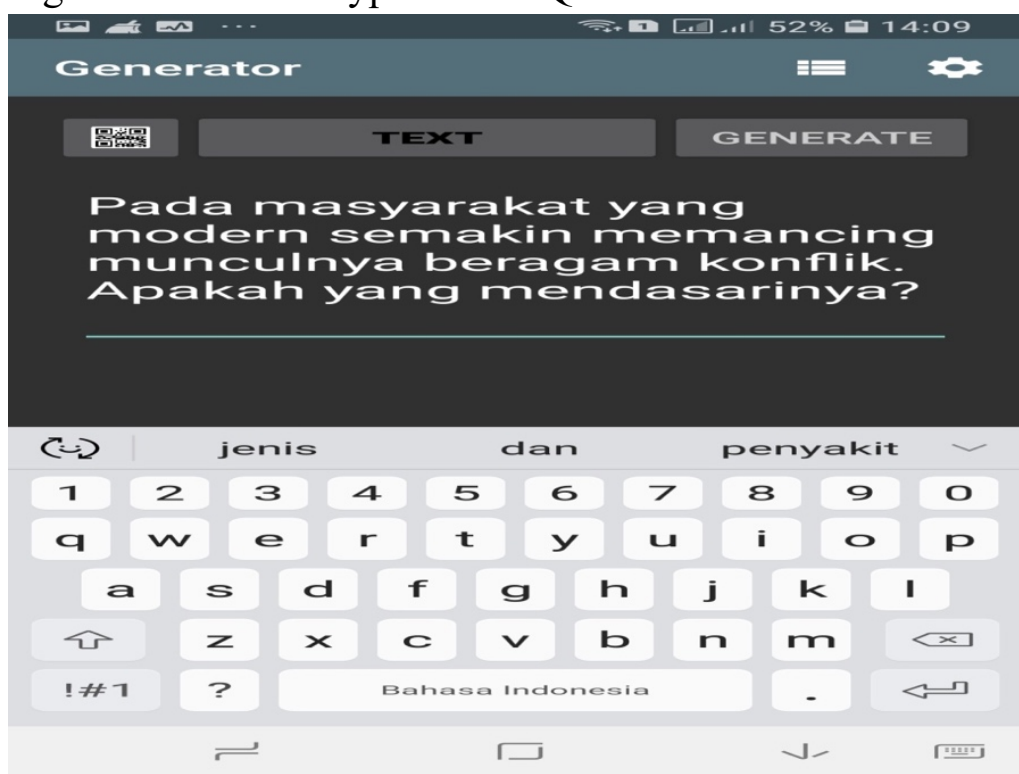

Figure 3 Questions typed on the QR Barcode Generator

Barcode Generator is the part that must be installed by subject teachers who will use the QR Code media in their learning. If in this case the sociology of learning material raised then the task of sociology teachers to install the barcode generator. After successfully installing, the next step the teacher writes the discussion material or questions in the barcode generator. The questions written must be in accordance with the theme of the material being conveyed or that is being discussed. For example, this week the discussion is related to conflict, then the questions typed in the barcode generator must be related to the discussion of social conflict. The results of the teacher's typing in the barcode generator are then saved and can then be printed out or printed out. The number of questions will be discussed as a group. So in essence, only teacher subjects who install a barcode generator. From the results of the discussion material or questions that have been saved or saved can be directly printed and then used in learning. Students who will then receive the printout. 
Figure 4. Form QR Code

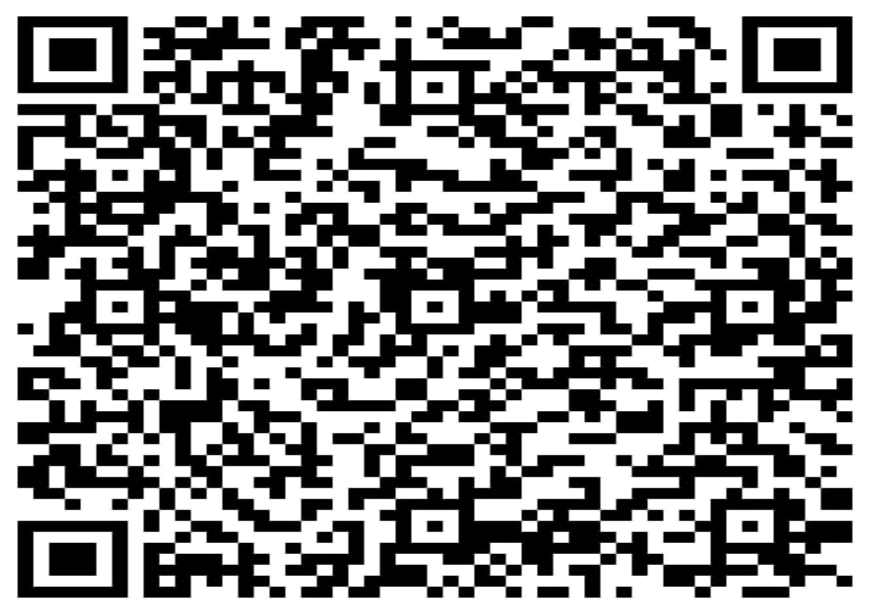

This QR Code is the part that students must download in order to find out the assignments or material given by the teacher in the form of a barcode. Once downloaded, it scans the printouts provided by the subject teacher. Using a smartphone, students download the QR Code. Because without downloading the QR Code it cannot scan the assignment of the teacher.

In every implementation of teaching and learning activities, it focuses on how to create a learning model that is creative, innovative, and does not cause boredom among students. In addition, the most important thing is the achievement of the expected learning objectives. The learning process is needed by placing students as the center stage performance, which is an interesting learning process so students can respond to learning with a pleasant atmosphere.

In essence, learning is a process marked by changes in a person. So, learning here is defined as a process of permanent behavior change from the unknowing to being know, from not understanding to understanding, from less skilled, becoming more skilled, and from old habits to new habits, as well as to the environment and the individual itself. While the word teaching is done by the teachers is the process of stimulating and directing students to learn. How to teach good teachers is a key and prerequisite for students to have learned well.

On this occasion the material raised by using smartphones as learning media was the subject of social conflict. Students who have a smartphone download the QR Code first on Google Play. Then scan the questions given by the teacher or teacher in the form of barcodes. After scanning, students will see problems that must be resolved by group discussion or individually. The advantages of this model are students can utilize their sophisticated smartphones for useful learning. So here smartphone functions are not only used for social media such as chatting via WA, BBM, Line, Facebook, Instagram, viewing YouTube, playing online games, etc., but can also be used for positive learning to increase competence and achievement 


\section{Use of QR Code media in class}

In the initial activity the teacher starts learning by giving greetings, praying together, reading Asmaul Husna and singing Indonesia Raya. Then the teacher does attendance. The learning process with QR Code media begins with giving apperception related to previous learning. In this case, the teacher gives questions to students about the previous material. Furthermore, the teacher gives an explanation of the competencies and material to be learned along with the methods that will be used in the learning process. Then the teacher asks all students to open the sociology handbook and read it for fifteen minutes.

On the subject matter in class xi specializing in social sciences about the material of social conflict and its resolution efforts, the authors carry out learning in groups. The advantages of working in groups include tasks that can be discussed internally in groups, can be mutually cooperative and also practice tolerance. In addition, working in groups accelerates work time and also raises a sense of competition between groups so that each individual in the group is always motivated to perform the group is the best.

The next step is to form a class into 5 groups in which there are about 6-7 people. You do this by using a count, starting counting from number 1 to number 5 and can start from the back row or front row. When the teacher says counting starts, each student starts counting until everyone gets a group. Then, students will join with other students in accordance with the numbers mentioned earlier. After coordinating internally, appoint one of the preferred students who have a smartphone. The task he does is download the QR Code and then scan the material or group assignments from the teacher.

After each group scans several questions the next step is to carry out discussions in the group. Following is the learning procedure using the QR Code media (1) The printout results from the barcode generator by the teacher are posted in several places in the school area. The number of print outs containing questions is six sheets. So each student in the group gets a ration in turn to do the scanning with QR Code. Meanwhile, to find out the location of the barcode scanner printout results, instructions have been given by the teacher concerned, how do the group members direct them, (2) Then each group competes to find and scan after downloading the QR Code, (3) After that the students assigned to do the scanning return to the group with the results of the questions from the scanning results on a smartphone, (4) Then discuss and write on the results sheet of the discussion and submit to the teacher, (5) The activity continues continuously until all six questions can be answered by all groups. And the group that can complete the task first will get additional points, (6) Each group appoints one of its members to present the results of the discussion and the other groups are tasked with responding it, (7) After all groups have progressed, the teacher's task is to provide evaluation and assessment. 
Here are the pictures that show learning QR Code media: Figure 5. Printout of QR Code

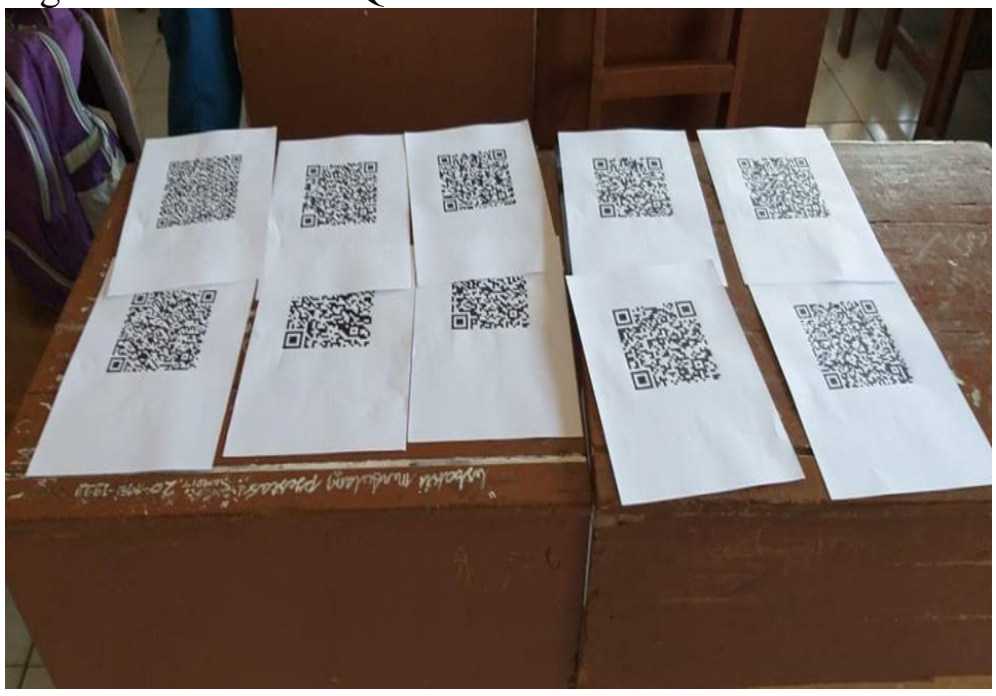

Figure 6. Representation of each group

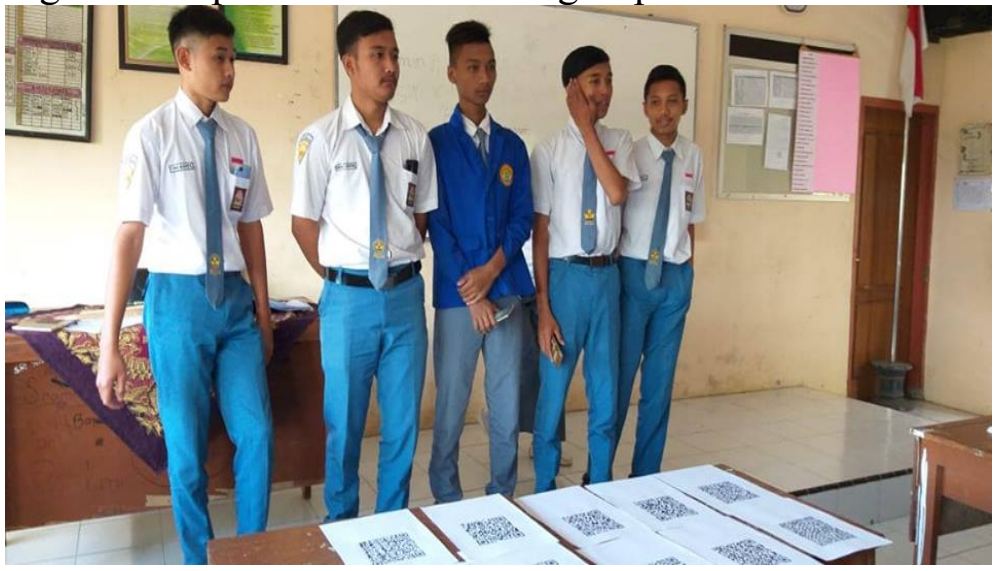

Figure 7. The process of students doing QR Code Scaning

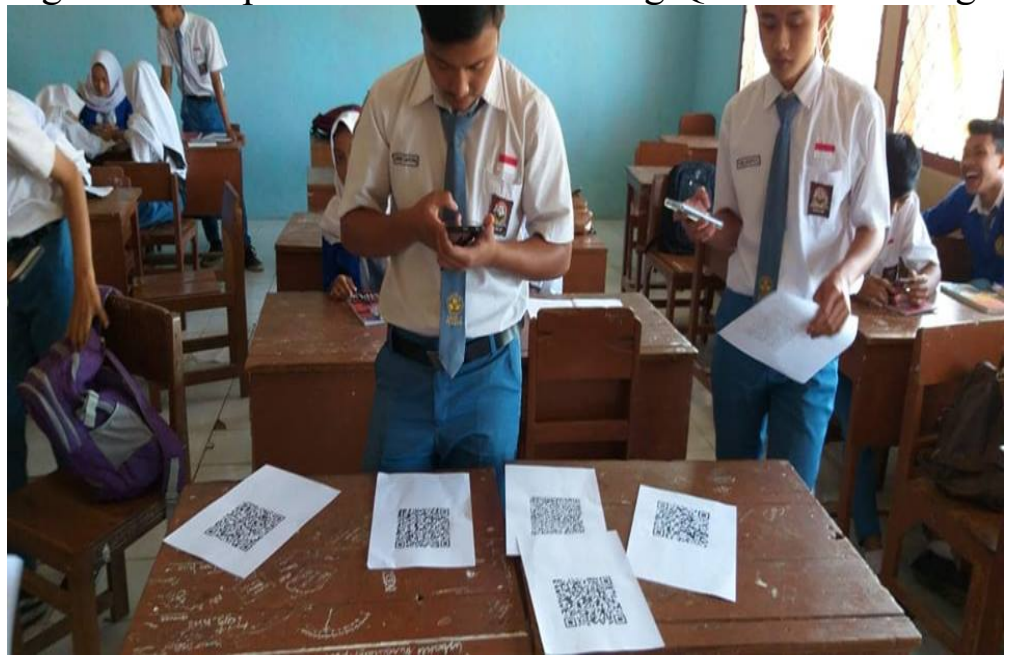


Figure 8. The process of scanning QR Code

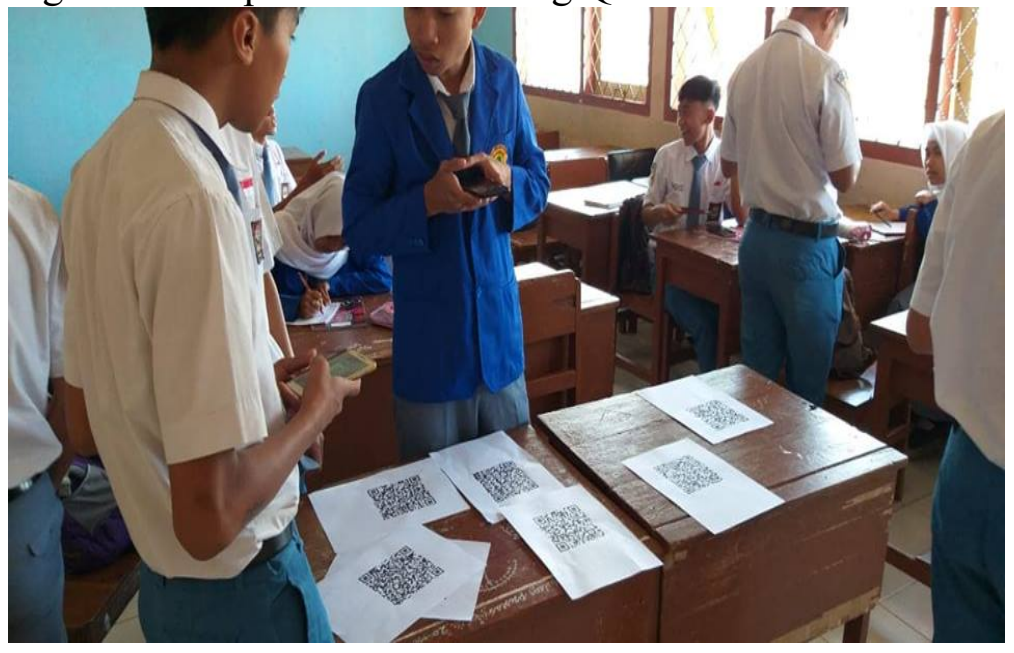

Figure 9. Results in the form of tasks / questions from QR Code scanning

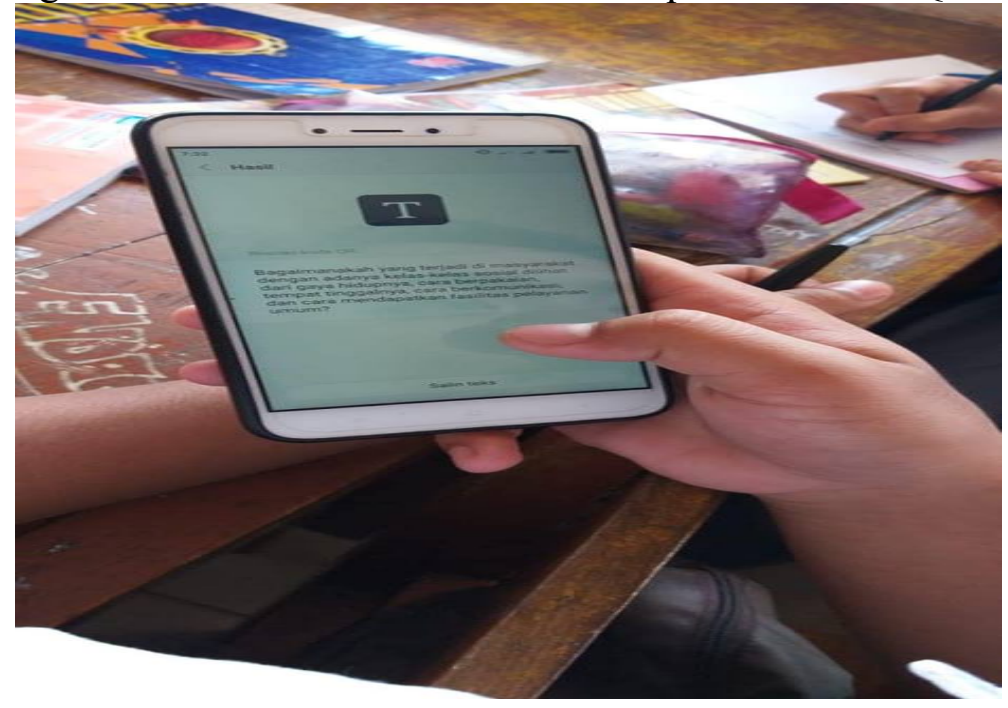

Figure 10. Work on the tasks from the results of scanning QR Code

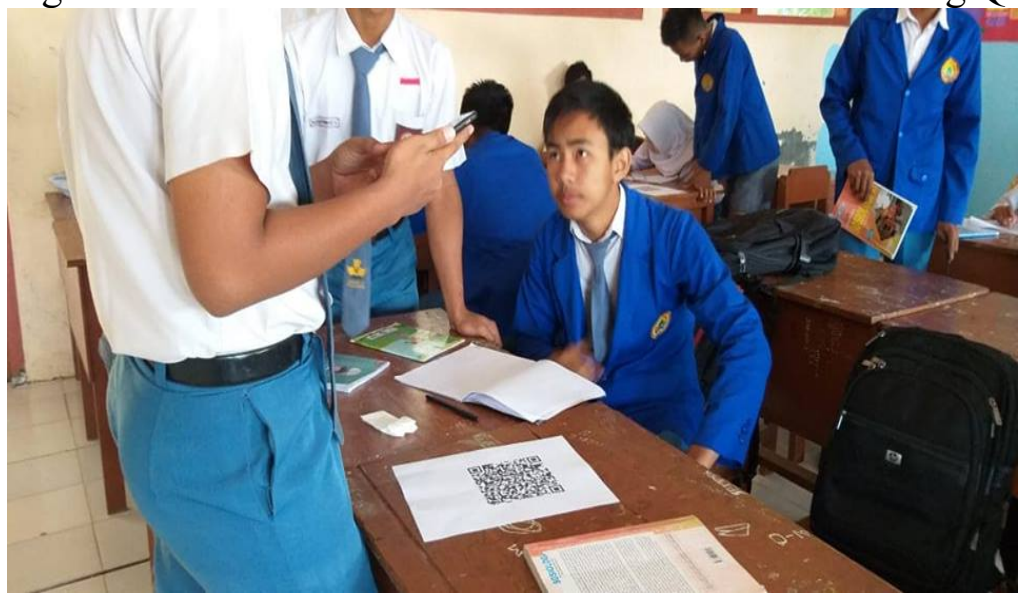


Figure 11. Actualization of 4C (Critical, Creative, Communicative and Collaborative)

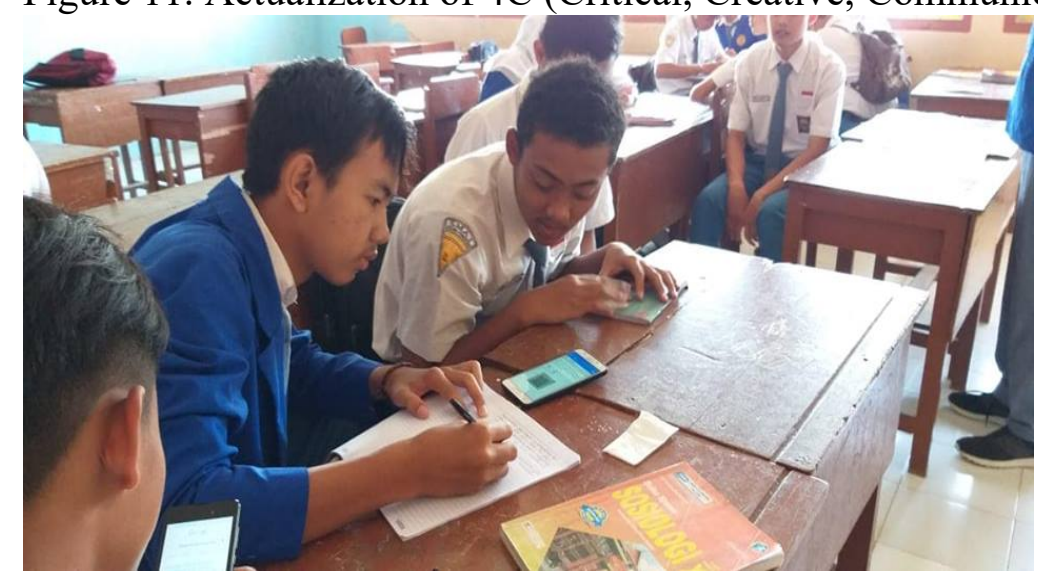

After applying learning using the QR Code media the results achieved were very significant. Students become more motivated and excited in the learning process. By utilizing smartphones, students can use them for learning with the aim of fostering interest in sociology subjects, especially conflict material. The students were very enthusiastic about doing and completing group assignments as expected. This can be seen from each group conducting discussions and timely gathering the results of discussion reports. The application of learning with QR Code media in understanding conflict can obtain the following results:

a. Students become increasingly active in the learning process The application of learning methods using the QR Code media in class xi specialization in the social sciences in studying social conflict material shows that students are very enthusiastic in following the course of learning. Looks cheerful with the seriousness of students learning activities. Compared to the lecture method, the QR Code method proved to be able to increase the activeness, motivation, and interest of students. All students play an active role in communication, collaboration, creative activities and also think critically in the learning process.

b. The significant interest and enthusiasm of learning from students grows The impact that can be generated from learning methods with the QR Code media application is that students become more enthusiastic and motivated to learn conflict material. They in groups look excited, work together, communicate, and enjoy each and every step of the learning. Even students can complete the discussion task on time and provide answers in accordance with the answer guidelines. Besides that, it can be seen the character of cooperation, tolerance, and mutual cooperation while learning is taking place. 


\section{Obstacles encountered}

Some of the obstacles that can be found during learning by using QR Code media are as follows:

a. To download QR Code, a sophisticated smartphone is needed where there must be a Google Play application on the smartphone of the students.

b. Because learning is done outside the classroom, it is likely to interfere with other class teaching and learning activities.

\section{Alternative Development}

Based on the experience of the learning that has been carried out, so as to achieve maximum results and also obstacles encountered can be further minimized in the future it can be developed for the strategies that have been implemented with alternatives as follows: (a) Because it relates to downloading the Google Play application, adequate wifi needs to be prepared at school, (b) Reward or award given by the teacher can be added by giving gifts in the form of items that have value for students (c) Light sanctions can be given to groups that collect improperly from the time agreed upon.

\section{CONCLUSION}

1. The use of learning media with QR Code media is an appropriate means for students to have the willingness to work on and complete assignments to understand social conflict material. The activity begins with a question and answer session between students and teachers at apperception. The question is limited to matters relating to conflict. The aim is to remind students about the material. Then proceed to form groups where one group consists of 5-6 people. Cultivated in one group there are students who have smartphones so that they can be used to download QR Code media. After the group is formed, one group member downloads the QR Code media on Google Play. This is done for scanning material or assignments given by the teacher in the form of barcodes. By scanning it will appear or appear questions that must be discussed by each group. The results of the discussion are written back on the sheet and handed over to the teacher who teaches. After all groups submit the results of the discussion sheet, the teacher will randomly call the group that will advance the presentation and this takes place alternately. The next step the teacher evaluates the work of each group as a whole.

2. The use of QR Code media can be a means for students to practice accuracy in collecting assignments. The learning done in the form of groups allows the emergence of competition between group members. The competition arises when each group competes against each other first than the other groups. It is not uncommon for students to collide with other participants when looking for print 
out patches from the QR Code provided by the teaching teacher. You can see the joy, excitement, interest and enthusiasm to take part in learning without feeling sleepy. This learning makes students become more able to express themselves. Besides that, it also trains the willingness and accuracy to collect assignments given in groups by the teacher's teacher. Seeing the enthusiasm of the students, the writer became convinced that creative and innovative learning methods were highly expected by the students. And monotonous learning methods such as lectures have started to be disliked by students.

3. Some supporting factors that are very helpful in the application of learning methods with QR Code media are:

a. Students are very actively participating in this game so it makes the learning process fun;

b. The provision of rewards or rewards to each group, namely the existence of assessments makes students compete with one another to complete their assignments on time and then presentations;

\section{SUGGESTION}

As for some things that need to be considered to improve learning in the future are as follows: (1) Attention needs to be taken in utilizing time for the learning process, because the time required is longer so the material is difficult to convey in its entirety; (2) The values of togetherness, mutual cooperation, tolerance, and cooperation should always be instilled in students in the learning process, so that they can shape the character of students to be better than before.

\section{REFERENCES}

Kun Maryati / Juju Suryawati. 2017. Book Sociology of Social Sciences Specialization Group for SMA / MA Class XI. Jakarta: Esis.

Lia Candra Rufikasari. 2016. Sociology Student Book Specialization in Social Sciences for SMA / MA XI. Surakarta: CV Mediatama.

Sri Subekti, 2018. Printing Smart Generations Through Critical Thinking Learning. Surabaya: CV. Copyright Media Education.

Sri Subekti, 2018. Becoming a Productive Innovative Teacher: A Guide to Designing Innovative-Productive Learning in accordance with the 2013 Curriculum. Surabaya: CV Cipta Media Education.

Trianto Ibnu Badar Al-Tabany, 2014. Designing Innovative, Progressive, and Contextual Learning Models. Jakarta: Learning and Learning: Oriented Education Process Standards. Jakarta: PT Kharisma Putra Utama.

Smartphone. Accessed on July 21 from https://id.m.wikipedia.org.

QR Code as a Learning Media by Drs. Iwan Rudi, Setiawan. M.M was delivered on the homepage of Teacher Literacy, October 23, 2018 Accessed on July 20, 2019 from smansabaliterasi.blogspot.com. 